\title{
Histopathology and Cytopathology in the Era of COVID-19 Pandemic
}

\author{
Samina A Khanday $\mathrm{MD}^{1}$, Ruby Reshi $\mathrm{MD}^{2}$, Neelofer Gul MD${ }^{1}$, Majid Mushtaque MS, $\mathrm{FNB}^{3 *}$
}

${ }^{1}$ Registrar, Department of Pathology, Govt. Medical College and Associated Hospitals, Srinagar, J \&K, India

${ }^{2}$ Professor and Head, Department of Pathology, Govt. Medical College and Associated Hospitals, Srinagar, J \&K, India

${ }^{3}$ Surgeon Specialist, Department of Health and Family Welfare, Govt. of J \& K, Kashmir, India

\author{
DOI: $10.36348 /$ sjpm.2020.v05i05.012 \\ | Received: 14.05.2020 | Accepted: 21.05.2020 | Published: 23.05.2020 \\ *Corresponding author: Dr. Majid Mushtaque
}

Abstract

COVID-19 (Coronavirus disease 2019) is a highly contagious infectious disease caused by severe acute respiratory coronavirus 2 (SARS-CoV-2) in humans. It primarily spreads from person to person through respiratory droplets or by aerosols and less commonly by contact with infected surfaces or fomites. Pathologists and their technical staff can become exposed to potentially infectious patients and specimen. The current article provides a brief description of the current knowledge of the disease and the measures to be taken by the concerned health care workers to minimise their risk of contracting the virus during the ongoing pandemic.

Keywords: COVID-19 (Coronavirus disease 2019), severe acute respiratory coronavirus 2 (SARS-CoV-2), Histopathology, FNA, Cytology, Disinfection, Precautions, Guidelines.

Copyright @ 2020: This is an open-access article distributed under the terms of the Creative Commons Attribution license which permits unrestricted use, distribution, and reproduction in any medium for non-commercial use (NonCommercial, or CC-BY-NC) provided the original author and sources are credited.

\section{INTRODUCTION}

COVID-19 (Coronavirus disease 2019) is an infectious disease caused by severe acute respiratory coronavirus 2 (SARS-CoV-2) in humans. The first case of COVID-19 emerged from Wuhan, Hubei province of China in early December 2019. A month later, the World Health Organization (WHO) formally declared it as a Public Health Emergency of International Concern and on March 11, 2020, the WHO declared it as a pandemic [1].

As on May 14th, 2020, the COVID-19 has spread to 215 countries with more than 4.4 million people infected and 300,229 deaths worldwide. United States of America has been the worst hit with above 1.4 million cases and 85,363 deaths till date. The first case of COVID-19 in India was reported on 30 January 2020 in the Kerala state. In the current scenario, we do not know the exact status of COVID-19 in our population in India, although data suggest about 79,333 cases with 2,564 deaths till now [2]. Presently the country is under a lockdown which has to end in a phased manner because of global socio-economic reasons. Consequently, one may see a sharp surge in COVID-19 cases in coming weeks in India. Even when the curve flattens, virus will not be completely eliminated from the environment, and we have to learn to live with the virus till either herd immunity is established or a curative medicine or vaccine is invented.
As the disease is caused by a novel coronavirus, the exact pathophysiology of the disease, its course, and therapeutics are not fully understood, as of now. Clinical presentation was varied, with most patients having respiratory tract symptoms [3, 4]. A study of 1,099 patients with COVID-19 showed that $19 \%$ presented with shortness of breath, $41 \%$ required oxygen supplementation, $5 \%$ became critically ill, and $2.3 \%$ required invasive mechanical ventilation [5]. According to the current data, SARS-CoV-2 primarily spreads from person to person through respiratory droplets. There are also reports that the virus may be aerosolized during certain activities (e.g., singing, speaking loudly) or procedures (e.g., intubation, CPR or the use of nebulizers) and that it may linger in aerosols for more than 3 hours [6]. SARS-CoV-2 RNA has been detected in blood, stool, as well as in the peritoneal fluid in COVID-19 patients [7, 8].

Apart from a number of health care measures advised to general population including social distancing and frequent hand sanitizations, health care facilities have recommended minimizing the nonessential hospital visits and prioritizing the elective inpatient and outpatient procedures which can limit the spread of virus among the masses as well as among the health care workers. With the rapidly increasing number of COVID-19 cases worldwide, pathologists 
and other technical staff can also expect to encounter more of these patients presenting for interventions including FNAC (fine needle aspiration cytology) and are therefore susceptible to contracting infections. Moreover, the departmental staff may also receive potentially infected pathological specimen including resected organ tissues, oral scrapes, lavage, and sputum for examination [9].

The current article discusses the measures the pathologists and their team should take while dealing with the potentially infected pathological specimen or the patients during the current COVID-19 pandemic. The present guidelines are in line with the current recommendations of Indian Council of Medical Research, and Ministry of Health and Family Welfare,
Govt. of India, which may be updated in future if the need arises.

\section{Disinfection practice of Histopathology Specimen:}

The World Health Organization (WHO) recommends that all specimens collected for laboratory investigations should be regarded as potentially infectious. Health-care workers who collect, handle, or transport any clinical specimens should adhere rigorously to the standard precaution measures and biosafety practices to minimize the possibility of exposure to pathogens (Table-1) [10].

The Centers for Disease Control and Prevention (CDC) has also released an Interim Laboratory Biosafety Guidelines for Handling and Processing Specimens Associated with COVID-19 [11].

Table-1: World Health Organization standard precautions

1. Ensure that health-care workers who collect specimens use appropriate personal protective equipment (PPE)i.e. eye protection, a medical mask, a long-sleeved gown, and gloves. If the specimen is collected with an aerosol-generating procedure, personnel should wear a particulate respirator at least as protective as a NIOSH certified N95, an EU standard FFP2, or the equivalent.

2. Ensure that all personnel who transport specimens are trained in safe handling practices and spill decontamination procedures.

3. Place specimens for transport in leak-proof specimen bags i.e. secondary containers, that have a separate sealable pocket for the specimen i.e. a plastic biohazard specimen bag, with the patient's label on the primary specimen container and a clearly written laboratory request form.

4. Ensure that laboratories in health care facilities adhere to appropriate biosafety practices and transport requirements, according to the type of organism being handled.

5. Deliver all specimens by hand whenever possible. DO NOT use pneumatic-tube systems to transport specimens.

6. Document clearly each patient's full name, date of birth and suspected 2019-nCoV of potential concern on the laboratory request form. Notify the laboratory as soon as possible that the specimen is being transported.

Zhu et al., [12] have identified and characterized 2019-nCoV. The viral genome has been sequenced, and these results in conjunction with other reports show that it is $75 \%$ to $80 \%$ identical to the SARS-CoV and even more closely related to several bat coronaviruses $[12,13]$. Generally, there is a wide range of disinfectants available that can be used to disinfect surfaces. Kampf et al., [14] have noted that other coronaviruses (SARS and MERS), can persist on inanimate surfaces like metal, glass, or plastic for up to 9 days, but can be efficiently inactivated by surface disinfection procedures with $62-71 \%$ ethanol, $0.5 \%$ hydrogen peroxide, or $0.1 \%$ sodium hypochlorite within 1 min. All the work benches and surfaces should therefore be appropriately disinfected before and after the close of work.

Routine processing of histopathological specimen often inactivates many viruses, e.g. Ebola
[15]. Darnell et al., demonstrated that SARS-CoV can be inactivated by formalin and glutaraldehyde in a temperature and time dependent manner. While incubation at $4^{\circ} \mathrm{C}$ inhibited the effect of these chemicals, at $37^{\circ} \mathrm{C}$ or room temperature, formalin significantly decreased the infectivity of the virus on day 1, while glutaral-dehyde inactivated SARS-CoV after incubation of 1-2 days [16]. Duan et al., [17] found that several coronaviruses were made noninfectious after the following exposure for $90 \mathrm{~min}$ at $56^{\circ} \mathrm{C}, 60 \mathrm{~min}$ at $67^{\circ} \mathrm{C}$, or $30 \mathrm{~min}$ at $75^{\circ} \mathrm{C}$. He also reported that irradiation with ultraviolet light for $60 \mathrm{~min}$ on several coronaviruses in culture medium also resulted in undetectable levels of viral infectivity. Paraffin infiltration in most histopathology laboratories use a temperature of $60-65^{\circ} \mathrm{C}$ for $2 \mathrm{~h}$ or more. It is, therefore, appropriate to consider that the formalin fixed paraffin-embedded tissue block would have a low risk of coronavirus infectivity. 
As the virus may be aerosolized during certain activities or procedures and as it may linger in aerosols for more than 3 hours [6], it is necessary to contain aerosols generated in the cryostat while performing frozen sections. If this is not feasible, the frozen section procedures as well as grossing of partially fixed specimen should be avoided.

\section{FNA sampling and processing in COVID-19 Era}

Cytopathology residents may be expected to perform FNAs from any palpable swellings in suspected or confirmed COVID-19 patients. As the SARS-CoV-2 RNA has been primarily found in respiratory droplets and aerosols [6], any such procedure would qualify as close contact and, hence, mandates the use of a complete set of personal protective equipment (PPE) including laboratory gown, gloves, goggles, face shield, and N95 (or powered airpurifying) respirator [10]. At the minimum, the personnel are advised to don a surgical gown, cap, N95 mask, goggles, and adequate face shield.

All the patients who come for FNA should wear a mask during their interaction with the medical team. The mask may be removed briefly if it interferes with the procedure. During such a period, his/her head should be positioned in such a way that they preferably breathe away from the health care worker and should also be counseled not to cough during the entire procedure. Following the FNA procedure, the material should not be expelled from the needle as it may generate droplets and aerosols. However, if inevitable, the same should be expelled very gently from the needle. The personnel should hold their face as far as possible during this procedure. Again, while making a smear it is recommended that slides are held as far as possible from oneself [9]. Drying of the smears by shaking them or blowing air should not be done as this can lead to the generation of aerosol. Air-drying of the smears should be ideally performed in class II biosafety cabinets (BSCs) [11].

The used needles should be discarded in sharpresistant waste containers. The syringe hub should be cut and the entire syringe should be disinfected using solutions with proven action against enveloped viruses including $0.1-1 \%$ hypochlorite solution, ethanol in concentrations ranging from 62 to $71 \%$, and $0.5 \%$ hydrogen peroxide $[14,18]$.

Apart from FNAC, samples like sputum, bronchoalveolar lavage (BAL), endotracheal tube aspirates, and other respiratory secretions may be received in the cytology laboratory, which should be transported only by a trained hospital attendant as soon as possible. The samples should be considered potentially infectious and therefore, universal precautions need to be followed while handling such samples. The collected samples in sterile tubes/containers should be appropriately labeled, tightly-capped, and sent to the cytopathology laboratory either in a biohazard zip-lock bags kept inside a leakproof cryobox with a biohazard label or alternatively in a triple packaging system. 18 In sample processing steps like shaking, vortexing, and centrifugation, aerosol generation is likely which requires adequate PPE and performing these steps in class II BSCs $[18,19]$.

Fixation of samples in alcohol-based fixatives (alcohol concentration $>70 \%$ ) or formalin can lead to the reliable inactivation of the novel coronavirus. However, in the case of fixation is done using weaker alcohol-based fixatives, additional precautionary measures as indicated above need to be used [20]. Rapid onsite evaluation (ROSE) is an important measure to ensure the adequacy of specimens. However, during an epidemic of a virus with respiratory-transmission, like SARS-CoV-2, clinical judgement should be used to determine if ROSE is necessary for the success of the procedure. The personnel involved in ROSE technique should use PPE.

All the residual samples as well as sample tubes and containers should be disinfected by adding $0.1 \%$ sodium hypochlorite solution, $0.5 \%$ hydrogen peroxide, $62-71 \%$ ethanol, quaternary ammonium compounds, or phenolic solutions followed by discarding in separate biohazard waste bags labeled as COVID-19 [18, 19].

All laboratory-generated biomedical waste and the used PPE must be discarded into appropriately designated bins labeled as COVID and as per hospital policy. General safe laboratory practices, including training all personnel in the use of protective equipment, limiting access to the laboratory, frequent hand washing, and wearing PPE should be followed as recommended by the World Health Organization (WHO). In case of any symptom suggestive of COVID19 , the staff member should be referred to the dedicated COVID specialist team based on the clearly defined protocol for further management [10].

\section{CONCLUSION}

Whole world has changed in past few months due to novel corona virus pandemic. Certain measures have become part of the lives in general population including social distancing and frequent hand sanitization, which will remain as such for a period of time. Considering the highly contagious nature of the virus, medical professionals refraining from taking all the precautions while dealing with patients can possibly have catastrophic results. Current recommendations should be followed and appropriate safety measures should be also taken by the pathologists and other concerned personnel while dealing with the potentially infected pathological specimen or the patients during the current COVID-19 pandemic. 


\section{REFERENCES}

1. World Health Organization. Available from: https://www.who.int/dg/ speeches/detail/whodirector-general-s-opening-remarks-at-themediabriefing--on-covid-19---11-march-2020.

2. Worldometers.info/coronavirus

3. Young, B. E., Ong, S. W. X., Kalimuddin, S., Low, J. G., Tan, S. Y., Loh, J., ... \& Lau, S. K. (2020). Epidemiologic features and clinical course of patients infected with SARS-CoV-2 in Singapore. Jama, 323(15), 1488-1494.

4. Chen, N., Zhou, M., Dong, X., Qu, J., Gong, F., Han, Y., ... \& Yu, T. (2020). Epidemiological and clinical characteristics of 99 cases of 2019 novel coronavirus pneumonia in Wuhan, China: a descriptive study. The Lancet, 395(10223), 507513.

5. Guan, W. J., Ni, Z. Y., Hu, Y., Liang, W. H., Ou, C. Q., He, J. X., ... \& Du, B. (2020). Clinical characteristics of coronavirus disease 2019 in China. New England journal of medicine, 382(18), 1708-1720.

6. van Doremalen, N., Bushmaker, T., Morris, D. H., Holbrook, M. G., Gamble, A., Williamson, B. N., ... \& Lloyd-Smith, J. O. (2020). Aerosol and surface stability of SARS-CoV-2 as compared with SARS-CoV-1. New England Journal of Medicine, 382(16), 1564-1567.

7. Wang, W., Xu, Y., Gao, R., Lu, R., Han, K., Wu, G., \& Tan, W. (2020). Detection of SARS-CoV-2 in different types of clinical specimens. Jama, 323(18), 1843-1844.

8. Coccolini, F., Tartaglia, D., Puglisi, A., Lodato, M., \& Chiarugi, M. SARS-CoV-2 is present in peritoneal fluid in COVID-19 patients. Annals of Surgery. Retrieved from https://journals. lww. com/annalsofsurgery/Documents/SARS-CoV-2\% 20 is $\% \quad 20$ present\% 20in\% 20peritoneal\% 20fluid\% 20in\% 20COVID-19\% 20patients. pdf.

9. Srinivasan, R., Gupta, P., Rekhi, B., Deb, P., Nijhawan, V. S., Prasoon, D., ... \& Goel, M. M. (2020). Indian academy of cytologists national guidelines for cytopathology laboratories for handling suspected and positive COVID-19 (SARS-COV-2) patient samples. Journal of Cytology, 37(2), 67-71.

10. World Health Organization. (2020). Infection prevention and control during health care when novel coronavirus $(\mathrm{nCoV})$ infection is suspected: interim guidance, 25 January 2020. World Health Organization;

$1-5$. https://www.who.int/publications-detail/infectionpreven tion-and-control-during-health-care-whennovel-corona virus-(ncov)-infection-is-suspected20200125

11. https://www.cdc.gov/coronavirus/ 2019nCoV/lab/lab-biosafety-guidelines.html

12. Zhu, N., Zhang, D., Wang, W., Li, X., Yang, B., Song, J., ... \& Niu, P. (2020). A novel coronavirus from patients with pneumonia in China, 2019. New England Journal of Medicine. 382:727733.

13. Perlman, S. (2020). Another decade, another coronavirus. New England Journal Medical, 24;382:760-762.

14. Kampf, G., Todt, D., Pfaender, S., \& Steinmann, E. (2020). Persistence of coronaviruses on inanimate surfaces and its inactivation with biocidal agents. Journal of Hospital Infection.

15. Henwood, A. F. (2018). Ebola and histotechnologists. Journal of Histotechnology, 41(2), 71-73.

16. Darnell, M. E., Subbarao, K., Feinstone, S. M., \& Taylor, D. R. (2004). Inactivation of the coronavirus that induces severe acute respiratory syndrome, SARS-CoV. Journal of virological methods, 121(1), 85-91.

17. Duan, S. M., Zhao, X. S., Wen, R. F., Huang, J. J., Pi, G. H., Zhang, S. X., ... \& Dong, X. P. (2003). Stability of SARS coronavirus in human specimens and environment and its sensitivity to heating and UV irradiation. Biomedical and environmental sciences: BES, 16(3), 246-255.

18. Tan, S. S., Yan, B., Saw, S., Lee, C. K., Chong, A. T., Jureen, R., \& Sethi, S. (2020). Practical laboratory considerations amidst the COVID-19 outbreak: early experience from Singapore. Journal of Clinical Pathology.

19. Centers for Disease Control and Prevention. Laboratory Biosafety Guidelines for Handling and Processing Specimen Associated with SARS-CoV. Available from: https://www.cdc.gov/sars/guidance/f-lab/ app5.html.

20. Pambuccian, S. E. (2020). The COVID-19 pandemic: implications for the cytology laboratory. Journal of the American Society of Cytopathology. 